\section{The Rationality of Perception: Replies to Lord, Railton, and Pautz} Susanna Siegel

Book symposium forthcoming in Philosophy and Phenomenological Research

\section{Introduction}

The main task of The Rationality of Perception is to construct an epistemology of perception according to which perceptual experiences can be rational or irrational. On this picture, experiences are susceptible to rational evaluation. The Rationality of Perception thesis is that both perceptual experiences and the processes that give rise to them can be rational or irrational.

The epistemic roles that I attribute to perceptual experiences are best brought out by a subclass of cases in which perceptual experiences are heavily shaped by prior outlooks. These cases are designed to bring specific kinds of epistemic flaws in inference into focus by providing concrete examples in which we can see the flaws operate. For instance, consider a preformationist who holds this theory on poor grounds and claims to see embryos in spermcells viewed under a microscope. If his visual experience presented him with spermcells, and did so because he favored preformationism, I argue, his visual experience would inherit the poor epistemic status of his belief in preformationism. Both that belief and the perceptual experience would be redound poorly on his rational standing.

Cases like these belong to a two-pronged strategy in defending the idea that experiences are epistemically appraisable. The first step is to argue that experiences are made epistemically less powerful by certain influences. This step occurs in my discussion of epistemically less powerful by epistemic down psychological precursors to perception, such as belief or fears, can drain all or part of the epistemic power from experience. For instance, the Downgrade Thesis predicts that the preformationist's expentence contributes less to his reason to belie if it weren't hijacked by his ill-founded belief.

The second step argues that inference can explain the epistemic downgrade (chapters 5-7) The conclusions of inferences are rationally evaluable, and so if perceptual experiences are such conclusions, they will be rationally evaluable.

The Downgrade Thesis and the main claim of The Rationality of Perception are distinct but related. If experiences can be epistemically rational or irrational (and more or less so), the this fact can explain why an experience's psychological precursors can reduce or enhance its justificatory power. The Rationality of Perception idea can explain the Downgrade

Thesis.
The Rationality of Perception thesis raises so many questions about the epistemic roles of perceptual experience that what's needed, in my estimation, is a constructive defense of it: an account of how inference could affect the epistemic powers of perceptual experience. My constructive defense aims to show that it is coherent and plausible that perceptual experience plays epistemic roles that make it rationally susceptible.

As part of my constructive defense of the Rationality of Perception thesis, I defend an approach to inference according to which inferring is a distinctive way of leveraging information one has already into a new informational state. When it is formed via such a response, the new informational state is the conclusion of the act of inferring. I argue that nothing precludes perceptual experiences from being such conclusions. So part of my defense is a general theory of inferring in general. My target is the kind of inferring the redounds well or poorly on the subject's rational standing. Many of the low-level processes called "inference" in psychology would not qualify.

A standard and intuitive theory of inference holds that when one infers $p$ from $q$, the inferring happens (in part) because the subject reckons that q to support $\mathrm{p}$. The "reckoning"-state is an informational state of its own, distinct from the premise-state with content $q$ and the conclusion-state with content $p$. By occupying the reckoning -state, one represents q supports $\mathrm{p}$, and therefore represents a relation of epistemic support.

If inferring needed a reckoning -state, then no route to perceptual experience would be a good candidate for inference. My theory of inference rejects the need for a reckoning -state. It therefore rejects the idea that acts of inferring are structured by premise-states, conclusion-states, and reckoning states, with the reckoning -state causing you to enter the conclusion state, given that you were already in the premise-state.

So far I've summarized the book's main claims using the preformationism example, a probably apocryphal story about the early users of microscopes that has made its way as a colorful side-comment into histories of embryology. ${ }^{1}$ The arc of the discussion begins with a philosophical problem that the book is aims to solve. The problem is that some cases structured like the preformationism example pose a simple question that has no straightforward answer. Can the preformationist get just as much reason from his experience as he could, if a phenomenally indistinguishable experience was not brought about by his prior belief in preformationism?

This is a Yes-or-No question, and neither answer at first seems entirely satisfactory. Answering Yes would respect the point that perceptual experiences are normally an excellent and indispensable guide to justified beliefs and knowledge about countless everything days. (Here as in the book, I set external-world skepticism aside). But this position also allows that the preformationist could transition from having an unjustified belief in preformationism to a very well-justified one, as the best explanation for why there's an embryo in the spermcell would be that preformationism is true. Such a transition seems a form of confirmation bias. Answering No respects the point about confirmation

\footnotetext{
1 Pinto-Correira (1997)
} 
bias, but seems at odds with the epistemic powers of experience. So we have a problem. I call it "the problem of hijacked experiences", to capture the sense that an outlook is illicitly steering the mind into a perceptual experience that is congruent. Not all influences on perceptual experience by one's prior outlook are epistemically problematic, but the ones that are problematic result in hijacked experiences.

As I turned this problem around in my mind, I thought through many different kinds of examples. The kinds of examples that ultimately moved me to favor answering No are a exanpl kind not often found in Angophone philosophy or perception, though they are widely discussed and depicted in many other lines of inquiry. These examples are drawn from historically specific phenomenon of racialized perceptions in the United States. In my reply to Pautz I elaborate on how these examples differ from a standard type of example in the philosophy of perception, such as seeing red spheres or ripe tomatoes, that abstract from social circumstances. Pautz relies heavily on the standard type of example. I argue that in normative contexts like this one, historically vivid examples should move us more powerfully than the socially abstracted ones on which Pautz bases his criticisms. Lord and Railton focus on the things I say about inference, and I begin by replying them.

\section{Reply to Lord}

Lord's first objection is that I overlook the possibility that reckoning states could be implicit, so that an inferrer would not have to be aware that they were in a reckoning state. I didn't discuss this option in The Rationality of Perception because the reckoning model is motivated by a self-awareness of condition on inference. ${ }^{2}$ Reckoning explains why in inference, one does not proceed as if in ignorance of what one is responding to. And proponents of the reckoning model, such as Paul Boghossian, treat inference as fundamentally a form of reasoning that lends itself to self-awareness:

"Person-level reasoning [is] mental action that a person performs, in which he is either aware, or can become aware, of why he is moving from some beliefs to others." (Boghossian 2014, p. 16)

It is possible to develop reckoning models that divorce themselves from any self-awareness condition on inference, as Lord does. But since such reckoning models lack the powerful motivation given them by the self-awareness condition, they are not the most natural or most promising versions of the approach that I oppose.

Lord suggests that when you infer q from $\mathrm{p}$ without moving through any state of explicit reckoning, you can do that by conceiving of $\mathrm{p}$ as supporting $\mathrm{q}$. The beauty and promise conceiving $x$ as $y$ is that even unsophisticated creatures can have such conceptions. They don't need any of the sophisticated concepts that an explicit reckoning state would require, such as the normative concept of support. And they don't have to be aware that they are

${ }^{2}$ The proposal that reckoning states could be unconscious gets some air time in Siegel 2019, which is the main focus of Railton's contribution. concluding $\mathrm{q}$ because they take $\mathrm{p}$ to support it. But they're in a reckoning state all the same - an implicit one. Lord thinks I've overlooked this version of the reckoning model, and that is his second objection to the Inferential thesis.

My reply is that it is so easy to count as conceiving $x$ as $y$ that subjects will have many mplicit conceptions, and this permissiveness prevents Lord notion of conceptions from being useful in an analysis of inference.

Lord introduces conceiving $x$ as $y$ by noting something most of us have in common with dogs: we share a Newtonian mechanistic conception of the world "in virtue of" the fact that we expect bodies to behave in ways that "reflect Newtonian mechanics." [p. \#] This gloss suggests that having expectations that conform with a conception of $x$ as $y$ is sufficient for conceiving of $\mathrm{x}$ as $\mathrm{y}$. But consider any empirically equivalent theory $\mathrm{T}$, such as $\mathrm{T} 1$ that posits desires on the part of bodies that are efficacious under just the conditions that Newtonian forces would operate, or T1 that posits a monitoring God poised to intervene to make things happen in ways that conform to Newtonian predictions. If expecting the bodie to move in ways that conform to Newtonian mechanics is sufficient for having a Newtonian conception of the world, then it is also sufficient for having conceptions that correspond to T1, T2, and many other non-Newtonian theories. Implicit conceptions will proliferate.

Lord's point in introducing conceptions is to show by analogy what it would take for an inferrer to conceive of $p$ as supporting $q$. By concluding $q$ in response to $p$, the inferrer reflects that he implicitly conceives of $p$ as supporting $q$. But even if inferring reflects the conception of $p$ as supporting $q$, what stops the inferring from also reflecting other conceptions, such as the conception according to which I conclude q to avoid a bad consequence, or the one according to which I am exploring q to see what things are like if I do? For all Lord says about what it takes to conceive $\mathrm{X}$ as $\mathrm{Y}$, my concluding $\mathrm{q}$ from $\mathrm{p}$ will reflect many conceptions.

This multiplicity generates as dilemma. Either the conceptions reflected in concluding $\mathrm{q}$ from $p$ all collapse into one, or else they remain separate. If they all collapse, then it's hard to see why how this account is an account of reckoning. The conception that explains why someone concludes $q$ from $p$ is equally one on which she implicitly conceives of $p$ as supporting $q$, and one on which she implicitly conceives of $p$ in some other way. The collapse option appears unable to distinguish reckoning from accepting for the sake of argument, or accepting a conclusion under duress.

If the conceptions are separate, then something besides the mere act of concluding has to differentiate between reckoning and the other options I've listed. And that other ingredient is a chance to reintroduce the kind of self-awareness that Lord's type of reckoning state was meant to avoid.

yy Kindness case is meant to illustrate inference without reckoning. Lord thinks it illustrates inference with un-self-aware reckoning. According to him, the person at the post office infers that the clerk is kind, [presumably] because she conceives of the behavior she observes as kind behavior. 
I'm doubtful that conceiving $X$ as $Y$ gives us a viable account of inference without reckoning. Lord focuses on it because he thinks it promises an account of inference that would account for the Kindness case, but would not extend to inferences that result in perceptual experiences.

In the end, Lord agrees that hijacked perceptual experiences have an epistemic flaw, and he thinks the flaw is that they manifest dispositions to represent what is not actually there. This disposition is an epistemic vice. I think there must be more to the flaw than a disposition to have an incorrect experience, since we're all disposed to represent unequal lines when we see the Muller-Lyer diagram but that does not seem to be an epistemic flaw, beyond inaccuracy. ${ }^{3}$ The bad-making feature remains to be identified.

As I see it, when hijacked experiences are epistemically flawed, the flaw redounds poorly on the subject. Lord may be disagreeing, when he writes "[P]erceptions can manifest epistemic vice, even if they are a-rational". If a hijacked experience manifests an epistemic vice, why wouldn't that redound poorly on the subject's rational standing? And if it did, in what sense would the experience be a-rational?

Lord notes that both hijacked experiences and the types of selection effects I discuss manifest epistemic vice, and suggests that the category of epistemic vice provides a unifying account of the problem, whereas relying on inference to identify the bad-making feature doesn't encompass as many cases. I agree with both points, but I don't see why we should expect unity in bad-making features, given the wide range of ways in which outlooks can manifest in perception - by influencing patterns of attention, directions of inquiry, judgments made and actions taken in response to experience.

Another reason to expect disunity in the bad-making features is that perceptual experience is just one among many likely examples of mental phenomena whose epistemic evaluability is overlooked by anglophone epistemology. Patterns of association, directions of inquiry, products of imagination, core cognition, emotion, perceptual learning, and implicit attitudes are all potential manifestations of epistemically evaluable outlooks, and a case could made that each of these things are epistemically evaluable. ${ }^{4}$ Epistemic vice may be useful label for what happens when unjustified outlooks manifest themselves in any of these phenomena or in perceptual experience, but so long as the exact bad-making features remain underspecified, it is more useful as a label than it is as an analysis of what's going wrong. Inference is a useful way to unearth the bad-making features in some of these cases, but not in all of them. Given their diversity, it does not count against the inferential thesis if it gives us only a partial guide to the contours of epistemic evaluability in the mind.

${ }^{3}$ And on some approaches, even inaccuracies can facilitate successful navigation through the environment. Akins 1996, Prettyman 2019.

"For relevant discussion, see Myers (ms) on imagination, Jenkin (2020) on core cognition and perceptual learning, Vance (2014) on emotion, Brownstein (2019) and Beeghly and Madva (2020) on implicit attitudes, attention, Watzl (forthcoming) on attention, an Friedman (forthcoming) on directions of inquiry.

\section{Reply to Railton}

Railton agrees with me that inferring does not need a reckoning-state. He reads me as saying that inferring has no further structure, beyond the idea that inferring is a distinctive type of rationally evaluable response that leverages information one has already, resulting in an epistemically evaluable state. (The information could be misinformation). And here he disagrees, on the grounds that defining inferring in this way would include reinforcement learning, which occurs by a process of association, and don't support any flexibility in leveraging information.

For instance, if a rat got to the end of the maze by reinforcement learning by association, it is disposed to move to the cheese-spot, and the disposition is well-calibrated only as long as cheese is placed in the same spot. Moving the cheese or changing the maze would not lead the rat to move its path, absent another bout of reinforcement learning. But as it happens, rats who escape the maze can get to the cheese by scurrying across the top where it has never been before is using spatial map to infer that it can reach the cheese using a path that it did not previously use, and so was not part of its associative learning. Railton thinks inferring is distinct from reinforcement learning, and so inferring must have more structure than he takes me to say it has. Otherwise, reinforcement learning could meet the hallmarks of inference and so count by my lights as a kind of inferring.

agree with Railton that dispositions produced by reinforcement learning are distinct from inference, and a theory that lumped them together would lose track of the target

phenomenon. My reply is that this distinction is built in to the distinctive type of response that inferring is. The question is then how much the distinctive type of response can be chas charactering to bring it into focus, and I could have added to the dispositions produced by reinforcement was discussing states structured as associations, rather than states that result frem, but associative learning process)

Railton goes farther, by trying to explain how leveraging could happen without a reckoning-state. He asks: How could responses to information encode "relations of evidential or means-end relevance in light of the individual's antecedent information"? Encoding such relations in a way that combines with them antecedent information would distinguish this kind of response from all the other kinds I discuss, as well as from the dispositions generated by reinforcement learning.

A dialectical point: an account of how such encoding could happen - or even better, how it does happen - would not be at odds with my approach to arguing that inferring does not need a reckoning-state. I called my approach "illumination without analysis" because I didn't think analysis was needed to show that there can be inference without reckoning not because I think there couldn't possibly be any analysis. Both in my paper "Inference without reckoning" and chapter 5 of The Rationality of Perception (where I give my theory of inference) I purport to give "reasons to think that the nature of inference may be illuminated even without positing any structure beyond what's posited by the hypothesis 
that inferring is a distinctive kind of response to an informational state, or to a combination of such states, that produces a conclusion." I aimed to illuminate inferring by contrasting inferential responses to other kinds, whereas Railton aims to illuminate inferring directly, by describing its inner workings. These approaches are compatible.

Railton's account appeals to model-based cognitive architectures that regulate the organism's interactions with the environment. Mental models store information about the spatial, causal, probabilistic, and means-end relationships between a large number of variables, forming an informational network that includes expectations about (inter alia) how the environment is likely to be, and these expectations get weighed against new information that diverges from what's expected.

All this sounds reasonable as a way of encoding relations of evidential support. How does it bear on the idea that perceptual experiences can result from inferences, and so be rationally evaluable? As Railton points out, model-based architectures need not generate any kind of rationally evaluable states. He suggests that a subclass of model-based learning systems belong to rationally evaluable systems, and that subclass are creatures who can "act under the idea of figuring something out". For instance, his character Sin-yee is trying to figure out whether she can leap over the puddle, and her ability to intend to figure something out is what makes her inferring the kind that ultimately redounds on her rational standing. "This intention, like any intention, binds together the various elements of her figuring out behavior, and explains why figuring out what to do about the puddle is her her response to the situation before her, rather than something that merely happens to her."

As a sufficient condition for having a rational standing, this proposal seems reasonable. If you intend to figure something out, and your intention plays the role Railton describes, than the activation of a mental model is rationally evaluable.

But I doubt that all cases of inferring involve such an intention. The closer one gets to perceptual expertise, the less likely there is to be any intention. And in examples like my Kindness case, where someone strikes you as kind, there need be no intention to figure out whether the person is kind, or what they're like. So while the mental models definitely help illuminate the nature of inference, they need more help from the factors that make the use of those models rationally evaluable. For cases without a unifying intention, we may need more of an account than Railton gives of what makes the use of a mental model redound well or poorly on a subject. We need such an account to make sense of cases of inferring that don't lead to perceptual experience, and once we have it, it seems that nothing precludes perceptual experiences from being able to result from inferring as well.

\section{Reply to Pautz}

Pautz focuses on the Downgrade Thesis. He finds that he has an intuition against it and concludes that perceptual experiences must be a-rational. As Pautz sees it the Downgrade Thesis is the main support for the idea that perceptual experiences can be rational or irrational. This idea would be significantly undermined, he thinks, if the Downgrade Thesis turned out to be false.

Pautz's main objection to The Rationality of Perception appears to be methodological. He thinks there are powerful intuitions against the Downgrade Thesis. These intuitions are directed at both examples and general principles, such as the principle of Probability Increase. In his main example, a perceiver undergoes an introspectively seamless transition from a hijacked hallucination to a non-hijacked and veridical perception. ${ }^{5}$ In this case, it is meant to be intuitive that the phenomenal continuity goes along with continuity of justificatory power.

Pautz wonders why I don't consider these intuitions decisive in countering both the Downgrade Thesis and the idea that perceptual experiences can be rational or irrational, especially since when I lay out the problem of hijacked experiences, I say I feel the force of the idea that perceptual experiences provide justificatory power in virtue of their phenomenal character.

I came to accept both the Downgrade Thesis and the more radical idea that experiences are epistemically evaluable after considering a range of similarly structured cases with vastly different subject-matters. The kinds of cases that ultimately moved me from the puzzle to my solution fill in psychological details of situations that actually occur, regularly, at specific places and times. For all we know, cases that meet my specifications have actually occurred, though it is not possible to find out. Whether they are actual or not, they are sociologically realistic. Whether they are psychologically realistic is still a matter of dispute.

By contrast, Pautz's cases are both psychologically unrealistic and socially abstracted. ${ }^{6}$ By conienst, Parz's cases are both psychologically un Experiences of red spheres abstract from the great complexity of perception, including any in torcal, psychologil, or social context. I think both types of in the philosophy of perception, and in philosophy generally. I's therefore crucial to understand when each type of example is a fitting one to use, especially when they pull in different directions - as they do when it comes to the Rationality of Perception thesis.

In Pautz's seamless transition example, an individual looks at a red sphere. Why this person is doing that, how it makes them feel, and who they are in relation to us or other people is not specified, because these things are not supposed to matter. And for many aspects of perception, these things don't matter. It has proved useful and important to consider pared-down to limit the type of experience to color experience, ignoring as many other features presented in experience as possible, such as temporal dynamics and social cues. By focusing on such cases, philosophers made enormous progress in developing theories of the invariant structures of visual experience. By omitting specifications of irrelevant things, one is not pretending that perceptual experiences occurs outside of any social context (whatever that would mean). No one thinks that when you actually see a red

${ }^{5}$ Similar cases discussed by Johnston (2004) and White (2014)
${ }^{6}$ On psychology of hallucination, see Macpherson (ed) 
any social situation. When there's no reason to think that these things would make a difference to the structural properties of perceptual experience, there is usually no reason to control for them either in thought experiments or real experiments.

But the things this type of example abstracts from might make a difference when we're discussing the boundaries of epistemic evaluability. When we're asking about the rational standing of our fellow human beings, it makes sense to consider cases that are close to the ones in which our normative notions are ultimately meant to apply. Social relations to the ones in which our normative and afect a dome veliefs. If we're asking what would be a reasonable state of mind for someone to be in, our complexity.

For this reason, in considering whether the scope of epistemic evaluability extends to perceptual experience, I found it useful to consider the historically realistic example of brutal yet culturally normal situation that recurs in the history of United States. Since my book probes the idea that perceptual experiences could redound well or poorly on a person, it's important to test this idea against perceptual situations that don't abstract from the kinds of complexities missing from cases like the red sphere. Those complexities are rightly missing when we're asking about the metaphysics of experience, but it's less obvious that such examples should be our paradigms when we're asking about justificatory power and rational standing. The features in perception we abstract away from might be relevant a perceiver's rational standing.

And I think that's just what we find. In the type of case I focus on there are massive protests and ince of is police (n) boy posed im a mo boy posed imine from people who live regularly with the threat of this kind of violence against them, their siblings, cousins, etc. and who therefore navigate the consequences of being perceived as threatening

Three examples: 2014 Ferguson. In explaining to a grand jury why it was reasonable for him to shoot his gun at 18 year old Michael Brown, Darren Wilson describes Brown as having "the most intense aggressive face. The only way I can describe it it looks like demon, that's how angry he looked."

demon, that's how angry he looked." 1973 rirst NYC police officer tried for murder while duty) acquitted for shooting to death 10 year-old

1964 Harlem riots. Officer Thomas Gilligan shot and killed 15-year-old James Powell in never becam part of public political life but show the same pattern of acquittal and indignance.
You could see the acquittals and the protests as a living disagreement about whether the beliefs were reasonable. What's culturally normal is both the legal classification of these beliefs as reasonable, and the refusal to accept that epistemic categorization of them, on the grounds that the fear deemed reasonable by legal institutions is an unreasonable cultural myth of the dangerous black boy or man, operating in the minds of individuals

My route to the Downgrade Thesis and the Rationality of Perception does not involve considering a perceptual scenario and then having an intuition about it. (For this reason, I wouldn't characterize the dialectical situation, as Pautz does, as "intuition-swapping"). Instead my reaction came from considering whether the massive reactions to the repeated Instead my reaction came from considering whether the massive reactions to the repeated hallucinated cues for danger (a menacing look, a gun, etc). Presumably many of the protestors think that is exactly what happened.

If someone always hallucinated a threatening situation when they saw you, and if the situation they hallucinated jibed with an entrenched cultural stereotype that imposed limitations on you, you'd be justifiably offended. “But it's just a hallucination - like seeming to see a red sphere", someone might say. This would be a poor defense, because in the context we're considering, it isn't just a hallucination. It's an experience that manifests a cultural situation, with a political dynamic operating through it. A cultural myth is operating through individual minds.

When I focus on the cultural myth operating in individual minds, it doesn't seem to matter whether its manifestation takes the form of perceptual experience or just belief. In particular, it does not seem incumbent on someone to whom the fear was directed to excuse the officers upon learning they their racist outlook had reached all the way to their pereptur I'm terrified (especilly when this person is armed), angry, offended, and I'm more incline Im terrifed (especialy when ths person is armed), angry, offended, and 'm more incl to think the hallucinator has an epistemic problem than I am to think they're being reasonable because their twisted outlook has infiltrated all the way to their perceptual
experience. It redounds poorly on him if the hallucinator can't see an ordinary male young person for what he is, whether he is an ordinary shoplifting teenager, or an ordinary youngster just going about his business. A perceptual experience does not give someone reason to think a person is dangerous, even if dangerous is the way the teenager (or child) looks to him.

These responses are at odds with the idea that the perceptual experiences provide justificatory support for thinking the person seen is dangerous, absent defeaters. If you're on the receiving end of such twisted perceptions, this conclusion might even seem plain. When such perceptual experiences are extensions of unjustified beliefs, the difference between perceptual experience and belief seems less significant.

Pautz writes "It would be wrong to suggest that opponents of DT must accept the obviously false claim that in these circumstances jill would be justified in shooting Jack. They only say that her believing that Jack's face has the anger-features (the content of her experience) is rational in her circumstances". But in cases where self-defense law is properly applied, 
having a perceptual experience of someone as threatening could go a long way toward making it reasonable to react violently in order to protect yourself. It becomes unclear why the person lacks reason for aggression, if their experience has just as much power as perceptual experiences typically do.

Pautz classifies my cases as "science fiction", but this is a misnomer. Science fiction is a genre in which things are depicted that violate the laws of nature. The scenarios I'm considering are hypothetical extension of all-to-realistic situations, well within Im consideng are hy nature. Abstracting from social context is appropriate for many questions in the philosophy of percepton, but when stcomes to whether hey redound well or poorly on the perceivers, we need to be able to bring our no whether ne lose clarity.

In addition to his methodological objection, Pautz raises two important residual questions. First, he asks about the scope of the Rationality of Perception thesis: does it apply beyond visual experiences to include olfactory and auditory experience? Yes. The scope of the thesis is perceptual experiences, which are experiences that feel like perception of spatially located things. The sensory modalities can produce experiences that are not perceptual in this sense, as when one hears a noise but it seems to come from within one's mind with no directionality. And perhaps olfactory imagination when you imagine (or remember) a smell can produce a type of olfactory experience that is not perceptual. But perceptual

experiences in any modality are the ones the Rationality of Perception thesis applies to. Since experiences in this category purport to present us with things in the external world, they are all good candidates for having accuracy conditions.

Second, Pautz asks which of the norms that apply to belief also apply to perceptual experience. The Rationality of Perception thesis entails that perceptual experiences can redound well or poorly on a subject, depending on how those experiences are formed. I agree with Pautz that having experiences with contradictory contents need not be a mark of irrationality in itself (though see Byrne 2016 for the opposing view). In general, I think we can distinguish three main types of normative pressures on belief: coherence norms that govern the ways that adding or removing beliefs should affect the rest of one's mental state; evidential norms governing how one ought to respond to evidence; and normative pressures on what one should have beliefs about, for example in the form of norms of in quiry. It's possible and even likely that norms from these different categories may end up exerting opposing pressures. ${ }^{8}$ The fact that norms exert opposing pressures makes it implausible that they stand or fall as a whole. If coherence norms ended up not applying to experience, that wouldn't be a strike against the Rationality of Perception thesis.

\section{Bibliography}

${ }^{8}$ On a possible tension between coherence and evidential norms, see Worsnip 2018. On possible tension between evidential norms and norms governing what to have beliefs about see Friedman 2020.
Akins, K. (1996). Of sensory systems and the 'aboutness' of mental states. Journal of Philosophy, 93, 337-372.

Beeghly, E. and A. Madva. (2020) An Introduction to Implicit Bias: Knowledge, Justice, and the Social Mind. New York, NY, USA: Routledge.

Boghossian, P. (2014) What is inference? Philosophical Studies 169(1): 1-18.

Brownstein, M. (2019) The Implicit Mind. Oxford University Press.

Byrne, A. 2016. Epistemic Significance of Experience. Philosophy and Phenomenological Research. DOI: $10.1111 /$ phpr.12246

Research. DOI: 10.1111/phpr.12246

Jenkin, Z. (2020) The epistemic role of core cognition. Philosophical Review

Johnston, M. (2004) The obscure object of hallucination. Philosophical Studies 120

(113-83.

Macpherson, F. and D. Platchias, eds. (2013) Hallucination Cambridge: MIT Press.

Myers, J. (ms, 2020) The epistemic status of the imagination

Pinto-Correira (1997) The Ovary of Eve. Chicago: University of Chicago Press.

Prettyman, Adrienne (2019). Perceptual precision. Philosophical Psychology 32 (6):923944.

Vance, J. (2013) Emotion and the new epistemic challenge from cognitive penetrability. Philosophical Studies 169(2): 257-83.

Worsnip, A. (2018) "The conflict of evidence and coherence" Philosophy and Phenomenological Research DOI: 10.1111/phpr.12246

White, R. (2014) What is my evidence that here is a hand? In D. Dodd \& E. Zardin (Eds.), Scepticism and perceptual justification. Oxford: Oxford University Press. 